NBER WORKING PAPER SERIES

\title{
THE EFFECTS OF CARDIAC SPECIALTY HOSPITALS ON THE COST AND QUALITY OF MEDICAL CARE
}

\author{
Jason R. Barro \\ Robert S. Huckman \\ Daniel P. Kessler \\ Working Paper 11707 \\ http://www.nber.org/papers/w11707
NATIONAL BUREAU OF ECONOMIC RESEARCH
1050 Massachusetts Avenue
Cambridge, MA 02138
October 2005

\begin{abstract}
We would like to thank Richard Bohmer for helpful comments and advice, Robert McNary for exceptional research assistance, and the National Institute on Aging through NBER for generous support. Barro and Huckman also acknowledge support from the Division of Research and Faculty Development at Harvard Business School. The views expressed in this paper do not necessarily reflect those of any of the authors' institutions. The views expressed herein are those of the author(s) and do not necessarily reflect the views of the National Bureau of Economic Research.

(C2005 by Jason R. Barro, Robert S. Huckman, and Daniel P. Kessler. All rights reserved. Short sections of text, not to exceed two paragraphs, may be quoted without explicit permission provided that full credit, including (C) notice, is given to the source.
\end{abstract}


The Effects of Cardiac Specialty Hospitals on the Cost and Quality of Medical Care Jason R. Barro, Robert S. Huckman, and Daniel P. Kessler

NBER Working Paper No. 11707

October 2005

JEL No. I1

\section{ABSTRACT}

The recent rise of specialty hospitals - typically for-profit firms that are at least partially owned by physicians - has led to substantial debate about their effects on the cost and quality of care. Advocates of specialty hospitals claim they improve quality and lower cost; critics contend they concentrate on providing profitable procedures and attracting relatively healthy patients, leaving (predominantly nonprofit) general hospitals with a less-remunerative, sicker patient population. We find support for both sides of this debate. Markets experiencing entry by a cardiac specialty hospital have lower spending for cardiac care without significantly worse clinical outcomes. In markets with a specialty hospital, however, specialty hospitals tend to attract healthier patients and provide higher levels of intensive procedures than general hospitals.

Jason R. Barro

Bain and Company

jason.barro@post.harvard.edu

Robert S. Huckman

435 Morgan Hall

Harvard Business School

Boston, MA 02163

and NBER

rhuckman@hbs.edu

Daniel P. Kessler

Graduate School of Business

Stanford University

Stanford, CA 94305

and NBER

fkessler@stanford.edu 


\section{INTRODUCTION}

The debate over the welfare implications of specialty hospitals - for-profit, physician-owned institutions that serve patients with a particular illness, such as cardiac disease - involves several issues of long-standing interest to economists. Opponents of specialty hospitals argue that they are a vehicle to disguise kickbacks to physicians for referrals, and that they thereby contribute to the "medical arms race" of competition through the provision of medically unnecessary services. ${ }^{1}$ Opponents also argue that specialty hospitals "cherry pick" profitable services and healthy patients from general hospitals. Specialty hospitals, for example, are less likely than general hospitals to have emergency departments (US GAO, 2003b). In contrast, proponents argue that specialty hospitals are "focused factories" that not only offer their own patients more efficient specialized care but also lead neighboring general hospitals to become more responsive and up-to-date in their practices.

These opposing views have been manifest in two distinct policy perspectives. If competition from specialty hospitals has social benefits, then state regulators and public insurers such as Medicare and Medicaid should allow, and perhaps even facilitate, their entry. If competition from specialty hospitals has social costs, however, then policy makers should set regulations and financial incentives to account for the negative external effects that specialty hospitals create. As a result of this debate, the federal government imposed an 18-month moratorium in December 2003 on Medicare reimbursement for care at new specialty hospitals to allow for greater analysis of their impact.

\footnotetext{
${ }^{1}$ The concept of competition among health care providers leading to higher levels service provision is noted by Joskow (1980), Held and Pauly (1983), and Robinson and Luft (1985).
} 
Despite both practical and academic interest in this question, we are not aware of any existing research that has simultaneously estimated the effects of specialty hospital entry on health care costs and patient health outcomes; without information on both costs and outcomes, conclusions about welfare are necessarily speculative. In this paper, we assess empirically the two main hypotheses about specialty hospitals. We focus on the treatment of elderly Medicare beneficiaries with cardiac disease at single-specialty cardiac hospitals. Most of these hospitals are jointly owned by for-profit chains and the local cardiologists and cardiac surgeons who practice at the facilities.

First, we estimate how the Medicare expenditures, treatments, and outcomes for patients in geographic areas that experienced specialty hospital entry between 1996 and 1999 changed over this period. If specialty hospital entry leads to lower expenditures and better outcomes, we would conclude that it increases welfare. If it leads to higher expenditures and worse outcomes, we would conclude that it decreases welfare. If it leads to lower expenditures and worse outcomes (or higher expenditures and better outcomes), we would calculate the implied cost per life saved of specialty hospital entry to determine its welfare effects.

Our approach provides an unbiased assessment of the effects of specialty hospitals even if specialty hospitals select healthier patients for treatment, because it estimates the effect of specialty hospital entry by the difference in all patients' expenditures and outcomes - not just those for patients at specialty hospitals - between entry and control geographic areas. It identifies the direct plus any spillover effects of specialty hospitals. The consistency of these estimates depends on the assumption that trends in the unobservable characteristics of patients and markets in entry versus control 
areas are uncorrelated with the unobserved determinants of costs and outcomes. We investigate the validity of this assumption in detail below.

Second, we examine how the expenditures, treatments, and outcomes of patients admitted to a specialty hospital differ from those admitted to a general hospital in a 1999 cross-section of geographic areas with an operating specialty hospital. In addition, we estimate the extent to which differences in observable patient characteristics explain differences in the care of patients admitted to a specialty versus a general hospital. Although these estimates can neither prove nor disprove the existence of socially harmful behavior, they show whether the elderly patient populations at cardiac specialty hospitals are healthier in observable terms and quantify the importance of these differences for observed variation in costs and outcomes.

The remainder of this paper proceeds as follows. Section II describes the specialty hospital industry and discusses its potential implications for social welfare. Section III presents our empirical models. Section IV describes our data sources and methods, Section V presents our results, and Section VI concludes.

\section{SPECIALTY HOSPITALS: BACKGROUND AND IMPLICATIONS}

Specialty hospitals are not an entirely new phenomenon; hospitals focusing on treating children and psychiatric patients have existed for decades. However, as a 2003 US GAO report observes, new hospitals of this form differ from their earlier counterparts in several important ways. The new genre of specialty hospitals includes four types: cardiac, orthopedic, general surgical, and women's. Orthopedic specialty hospitals are approximately twice as common as each of the three other types, but cardiac specialty 
hospitals have much greater aggregate revenues (US GAO, 2003b, Table 2) than any of the other types. ${ }^{2}$ Most notably, these specialty hospitals are largely for-profit (93 percent of the specialty hospitals opened between 1990 and 2003 were for-profit (US GAO, 2003b, Table 1)) and owned at least in part by their admitting physicians. In fact, the median percentage of admitting physicians at specialty hospitals with ownership in that hospital was 73 percent in 2003 (US GAO, 2003b, Figure 1). ${ }^{3}$

In addition, these specialty hospitals are concentrated geographically in areas where state policy or local demographic conditions were favorable to hospital growth. Although 28 states in 2003 had at least one specialty hospital, approximately two-thirds of all specialty hospitals were located in seven states clustered in the western and southern portions of the country—Arizona, California, Kansas, Louisiana, Oklahoma, South Dakota, and Texas (US GAO, 2003b, p. 3). Of these states, Oklahoma was the only one that had a certificate of need (CON) program at any point after 1988, and that program did not cover cardiac services (Ho, 2005).

The debate over specialty hospitals centers around two hypotheses that have implications for social welfare. Arguments in favor of specialty hospitals focus on the potential for increased efficiency through either direct or spillover effects. Direct effects exist to the extent that specialty hospitals treat patients more efficiently than incumbent

\footnotetext{
${ }^{2}$ A 2005 report from the Center for Medicare \& Medicaid Services (CMS) noted several differences between cardiac hospitals and orthopedic/surgery hospitals. Relative to orthopedic/surgery hospitals, cardiac hospitals were characterized by a larger average daily census ( 40.4 vs. 4.5$)$, a higher percentage of facilities with an emergency department ( $71 \%$ vs. $4 \%$ ), a larger percentage of patient days attributable to Medicare (67\% vs. 36\%), and a smaller share of physician ownership (49\% vs. $80 \%$ ) (Center for Medicare \& Medicaid Services, 2005).

${ }^{3}$ Federal law, known as the Stark law, generally prohibits physicians from referring Medicare patients to facilities in which they have a financial interest. The law exempts physicians who have an ownership stake in an entire hospital from a ban on referrals to that hospital, under the assumption that the largest stake that a physician could have in this context would be too small to create significant moral hazard.
} 
general hospitals. In this vein, Herzlinger (1997) describes the benefits of specialty hospitals by viewing them as analogous to Skinner’s (1974) "focused factory."

The direct benefits of specialty hospitals could stem from three factors. First, given the substantial fixed investments required to provide services such as cardiac surgery or orthopedic procedures, specialty hospitals may be better able to exploit economies of scale by consolidating volume that would have otherwise been allocated across multiple diversified facilities. Nevertheless, despite compelling theoretical arguments, empirical evidence of economies of scale in hospitals has been limited. Dranove and Shanley (1995) find that hospital systems do not appear to have lower costs than otherwise similar "pseudo systems"-random collections of independent hospitals. Dranove (1998) finds evidence of scale economies in "non-revenue producing cost centers” (e.g., administrative services such as public relations, accounting, medical records, and data processing) for relatively small hospitals, but notes that these economies are exhausted in hospitals with more than 10,000 annual discharges (or roughly 280 beds). ${ }^{4}$

Second, the aggregation of volume by specialty hospitals may enable them to benefit from returns to experience that could either reduce cost or improve the quality of care. According to the GAO, although general hospitals typically have more beds than specialty hospitals, the focused mission of specialty hospitals often results in their treating more patients in their given fields of specialization (US GAO, 2003b, p. 5). The substantial literature on the positive association between volume and outcome (Luft, Bunker, and Enthoven, 1979; Luft, Hunt, and Maerki, 1987; Hannan et al., 1991, 1997;

\footnotetext{
${ }^{4}$ Dranove (1998) study does not test for economies of scale in clinical revenue centers on the assumption that the non-revenue centers represent the most likely source of scale economies.
} 
Huckman and Pisano, 2005) with respect to many surgical procedures suggests that such benefits may be obtained by single-specialty facilities that are successful in aggregating volume within a market.

Third, by allowing physicians to share in the efficiency gains through ownership, specialty hospitals may create more powerful incentives to achieve these and other cost and quality improvements. A report prepared by the Lewin Group on behalf of MedCath Corporation — a chain of specialty hospitals focused on cardiac care-finds support for these hypotheses, showing that patients at MedCath facilities had lower rates of riskadjusted patient mortality and shorter lengths of patient stay than a peer group of 1,192 hospitals performing cardiac surgery in the United States (Dobson, 2003).

Beyond these direct effects, the presence of specialty hospitals in a market may force competing general hospitals in the same market to become more efficient by threatening them with either declining prices or reduced share. Although no previous work has investigated the spillover benefits of specialty hospitals, Kessler and McClellan's (2002) finding that the presence of for-profit competitors leads to increased efficiency at nonprofits suggests that such spillovers may be important.

Critics of specialty hospitals, in contrast, argue that the same features of specialty hospitals that have the potential to make them more efficient also make them more likely to engage in behavior that reduces social welfare. For example, critics argue that specialty hospitals may be better able than general hospitals to focus on providing the types of treatments that are the most profitable, even if this is not in society's interest overall, because specialty hospitals do not care for patients with all types of illnesses. The fact that specialty hospitals allow admitting physicians to share in the institutions' 
profits can strengthen physicians' incentives to help pursue this objective, just as it can strengthen physicians' incentives to reduce costs and improve quality.

According to this reasoning, cardiac specialty hospitals' focus on technologicallyintensive services such as catheterization, angioplasty, and open-heart surgery is an example of such inefficient behavior. Although these services are highly profitable (Horwitz, 2005), the fact that the marginal health benefits of expansions in their supply are generally modest (McClellan, McNeil, and Newhouse, 1994) suggests that the welfare consequences of intensive treatments supplied by specialty hospitals may be questionable.

Along these lines, critics also argue that specialty hospitals may be better able to attract the most profitable types of patients. If patients with more severe forms of an illness are more costly to treat--and reimbursement systems such as Medicare's Prospective Payment System (PPS) do not fully compensate hospitals for this higher cost-then seeking out healthier patients can be a profitable business strategy. By law, no hospital can turn away an acutely ill patient; but, according to critics, because specialty hospitals have greater discretion over the types of services they provide, they can shape their patient populations indirectly by promoting services that healthier patients value more highly. The effect of patient selection within a given illness on hospital profits can be quite substantial. In fact, federal policymakers specifically excluded psychiatric hospitals from the Medicare PPS system on the grounds that psychiatric DiagnosisRelated Groups (DRGs) were not able to capture adequately the severity and cost differences among patients (Cromwell et al., 1991). 
Although shifting healthy patients from general to specialty hospitals does not, by itself, change total Medicare expenditures or any patient's actual care, it may have important implications for welfare in practice. If Medicare reimbursement for sick patients is less than their average cost, and Medicare must reimburse hospitals enough to enable all or virtually all of them to break even (e.g., Chalkley and Malcomson, 2000), then shifting only healthy patients from general to specialty hospitals can lead to increases in Medicare expenditures in aggregate. At the very least, such a transfer of resources to specialty hospitals from Medicare must be funded by taxation that imposes a deadweight loss. If such transfers give general hospitals the incentive to mimic specialty hospitals in order to compete, then they may distort medical care decisions as well.

Empirical evidence on the consequences of specialty hospitals shows that there is a basis for critics' concerns. Based on discharge data from the Healthcare Cost and Utilization Project from six states, GAO found that specialty hospitals treated a smaller percentage of severely ill patients relative to general hospitals in their geographic areas (US GAO, 2003a, figure 9). Cram et al. (2005) find that such differences in patient health status explain at least part of the difference in mortality rates at specialty and general hospitals. Consistent with the GAO’s results, Winter (2003) finds that centers specializing in outpatient surgery serve less-severe patients, on average, than the outpatient departments of full-service hospitals. Finally, Lynk and Longley (2002) present evidence suggesting that full-service hospitals suffer a decline in admissions of potentially profitable patients when ambulatory surgery centers, a close relative of specialty hospitals, enter the market. 
Yet despite the plausibility of both sides in the specialty-hospital debate, little work has investigated how specialty hospitals affect the cost of care. In addition, previous work has neither investigated the importance of spillover effects nor satisfactorily controlled for selection bias in assessing the effect of specialty hospitals on quality. By examining the consequences for Medicare expenditures and outcomes in markets where specialty hospitals have entered versus where they have not -- in addition to examining the consequences for patients at specialty versus general medical hospitals in markets with specialty hospitals -- this paper seeks to address both of these limitations.

\section{EMPIRICAL MODELS}

We estimate the effects of cardiac specialty hospitals on the expenditures on and quality of care for elderly Medicare beneficiaries with cardiovascular illness.

Specifically, we examine the impact of specialty hospitals on hospital expenditures, rates of use of specific intensive procedures, and health outcomes using longitudinal data on cohorts of elderly Medicare recipients who were hospitalized with incident illness in 1993, 1996, and 1999. We use models of two forms.

The first set of models investigates how time trends in expenditures and outcomes in hospital referral regions (HRRs) ${ }^{5}$ in which a specialty hospital opened in 1997 or 1998

\footnotetext{
${ }^{5}$ The Dartmouth Atlas of Health Care defines hospital markets at two levels. The finest level is referred to as the hospital service area (HSA). Most the 3,436 HSAs in the United States contain only one acute-care hospital; the distribution of total 1996 population across HSAs ranged from 604 to 3,067,356. Each of the 306 hospital referral regions (HRRs) represents a broader grouping of several HSAs; the distribution of total 1996 population across HRRs from 126,329 to 9,288,694. The Dartmouth Atlas describes the definition of these broader market areas as follows: "Hospital referral regions (HRRs) represent regional health care markets for tertiary medical care. Each HRR contained at least one hospital that performed major cardiovascular procedures and neurosurgery. In a similar fashion, HRRs were defined by assigning HSAs to the region where the greatest proportion of major cardiovascular procedures were performed, with
} 
(“entry” HRRs) differ from trends in HRRs in which no specialty hospital opened ("control” HRRs). The objective of these models is to identify the net direct plus spillover effects of specialty hospital entry on the care of patients in a hospital market. In 1997 or 1998, five cardiac specialty hospitals opened in the United States. These five hospitals were located in five different HRRs and were owned by three different entities.

The second set of models investigates how 1999 levels of expenditures and outcomes within an HRR differ between patients initially admitted to a specialty versus a general hospital. We estimate these models on HRRs that had an open specialty hospital as of January 1, 1999. The objective of these models is to identify the extent to which specialty hospitals treat patients more intensively and the effect of differences in patient mix between specialty and general hospitals on expenditures, treatments, and outcomes. In 1999, there were eight open specialty hospitals. These eight hospitals were located in seven different HRRs and were owned by six different entities.

In HRR $k$ during year $t=1993,1996,1999$, the observational units in our analysis are individuals $i=1, \ldots, \mathrm{N}_{k t}$ who are initially admitted to hospital $j$ with a new occurrence of illness. Each patient has a vector of characteristics $\mathrm{X}_{i t}$ : five age indicator variables (65-69 years, 70-74 years, 75-79 years, and 80-84 years; 85-89 years; omitted group 90-99 years), gender, race (black or non-black), and the patient’s hospital expenditures in the 180 days prior to the onset of the study illness. This final variable captures the overall status of the patient's health upon admission to the hospital. We also include diagnosis-code indicator variables for each of the following conditions: acute

minor modifications to achieve geographic contiguity, a minimum population size of 120,000, and a high localization index.” (Dartmouth Atlas of Health Care, 2004). 
myocardial infarction [AMI] (ICD9=410), ischemic heart disease [IHD] (ICD9=414), dysrhthmyia (ICD9=427), heart failure (ICD9=428), other heart conditions (ICD9 in 390429, except 410, 414, 427, and 428), or circulatory system disorders (ICD9=439-448). The omitted group among these indicators is that for cerebrovascular disorders (ICD9=430-438). Finally, each patient has a vector of indicator variables $Z_{j t}$ characterizing her hospital of initial admission (e.g., for-profit, nonprofit, or public ownership; system membership status; teaching status; and size).

We analyze three dependent variables. The individual incurs total Medicare inpatient hospital expenditures of $Y_{i t}$, where $Y$ is total expenditures in the year after and including the admission to the hospital for the study illness. The binary variable $\mathrm{C}_{i t}$ is equal to one if the individual receives one or more specific intensive procedures within a given interval (e.g., one day or one year) after the initial admission to the hospital and zero otherwise. The patient has health outcome $\mathrm{O}_{i t}$, where $O$ equals one if the patient has an adverse health outcome within 365 days of the initial hospital admission and zero otherwise.

The first set of models is of the following form:

$$
\begin{aligned}
& \mathrm{C}_{i t} \\
& \mathrm{Y}_{i t}=\gamma_{k}+\alpha\left(y 99_{t}\right)+\beta\left(\text { entry_y } y 99_{k t}\right)+\mathrm{X}_{i t} \phi+\mathrm{Z}_{j t} \delta+\varepsilon_{i t} \\
& \mathrm{O}_{i t} \\
& \mathrm{C}_{i t} \\
& \mathrm{Y}_{i t}=\gamma_{k}+\alpha_{1}\left(y 99_{t}\right)+\alpha_{2}\left(\text { trend }_{t}\right)+\alpha_{3}\left(\text { entry_trend }_{k t}\right)+ \\
& \mathrm{O}_{i t} \quad \beta\left(\text { entry_99 }_{k t}\right)+\mathrm{X}_{i t} \phi+\mathrm{Z}_{j t} \delta+\varepsilon_{i t}
\end{aligned}
$$

where $y 99_{t}$ equals one if the year is 1999 and zero otherwise; and $\gamma_{k}$ is an HRR fixedeffect. The interaction entry_99 $9_{k t}$, equals one if HRR $k$ is one of the five HRRs that experienced entry by a specialty hospital and the year is 1999 and is otherwise equal to zero. The variable trend $d_{t}$ equals zero if the year is 1993 and assumes a value of one or 
two if the year is 1996 or 1999, respectively. The interaction term, entry_trend ${ }_{k t}$, equals one if HRR $k$ experienced specialty hospital entry and the year is 1996; two if HRR $k$ experienced specialty hospital entry and the year is1999; and zero otherwise. Finally, $\varepsilon_{i k t}$ is an error term, where $\mathrm{E}\left(\varepsilon_{i k t} \mid \ldots\right)=0$. Equation (1) is estimated using data for 1996 and 1999 and is again estimated using data for 1993 and 1999 to examine the impact of the selected base year on our results. Equation (1a) is estimated using data for 1993, 1996, and 1999.

The coefficient of interest in these models is $\beta$. In (1), $\beta$ represents the difference in 1996-99 growth in outcomes between those HRRs that did and did not experience specialty hospital entry. In (1a), $\beta$ represents the difference in 1996-99 growth in outcomes in HRRs that did and did not experience specialty hospital entry, over and above the constant growth trend for the 1993-99 period. Put another way, model (1a) controls for preexisting differences in growth rates for entry HRRs in estimating the effect of specialty hospital entry.

The second set of models is of the following form:

$$
\begin{aligned}
& \mathrm{C}_{i t} \\
& \mathrm{Y}_{i t}=\alpha+\gamma_{k}+\beta\left(\text { specialty_hosp }_{j t}\right)+X_{i t} \phi+\mathrm{Z}_{j t} \delta+\varepsilon_{i t} \\
& \mathrm{O}_{i t}
\end{aligned}
$$

where specialty_hosp $p_{j t}$ equals one if hospital $j$ was one of the eight specialty hospitals open in 1999 and zero otherwise. In (2), $\beta$ represents the difference in 1999 levels of outcomes for patients initially admitted to a specialty versus a general hospital. 


\section{DATA AND METHODS}

We analyze patients with a new occurrence of cardiovascular illness in 1993, 1996, and 1999. ${ }^{6}$ We identified cardiac specialty hospitals (and HRRs that experienced specialty hospital entry) through a search of the trade press. We included both freestanding cardiac hospitals and cardiac hospitals-within-a-hospital. ${ }^{7}$ This broad inclusion rule should, if anything, bias our results against finding a difference between specialty and general hospitals. As described above, our search yielded five specialty hospitals that opened in 1997 or 1998, and eight specialty hospitals that were open as of January 1999. We define a patient as having had a new occurrence of illness in a given year if that patient was admitted in 1993, 1996, or 1999 with a diagnosis of cardiovascular illness without having been admitted with cardiovascular illness in the previous six months. Additionally, we exclude patients admitted to the hospital between January and June 1996 (because six months of claims data required to ensure the absence of prior admissions were not available for these individuals), patients who were in HMOs (because claims data is not available for Medicare HMO patients during our study period), patients suffering from end-stage renal disease, and non-elderly patients.

We use data from three principal sources in our analysis. First, we use the 20 percent Medicare Provider Analysis and Review (MEDPAR) file (for 1993) and the 100 percent MEDPAR file (for 1996 and 1999) to construct total Medicare payments (including patients’ deductibles and copayments) in the year after initial admission for a new occurrence of illness. Expenditures include all inpatient plus outpatient hospital

\footnotetext{
${ }^{6}$ We define cardiovascular illness as ICD9 codes 390-448, except 456, 459 and V43.

${ }^{7}$ Hospitals-within-a-hospital are specialty hospitals that are physically located on the campus of a general hospital but are separately licensed and certified. They generally have independent facilities such as operating rooms, physical therapy suites, and pharmacies.
} 
reimbursements (including copayments and deductibles not paid by Medicare) from insurance claims for all hospitalizations in the year following each patient's initial admission. $^{8}$

The diagnostic procedure used to assess artery status is cardiac catheterization or angiography (CATH), which may be followed by either coronary artery bypass graft surgery (CABG) or percutaneous transluminal coronary angioplasty (PTCA) to "revascularize," or remove blockages, detected by CATH. We construct indicator variables denoting whether each patient received each of these three intensive procedures in the day and the year after the onset of illness. We also tabulate each patient's expenditures on acute hospital care in the 180 days prior to admission for his study illness, as a measure of individual health status on entry to the study cohort. We measure the occurrence of complications with a variable indicating whether the patient was readmitted within one year with a subsequent episode of AMI or heart failure. ${ }^{9}$ Data on patient demographics were obtained from the Health Care Financing Administration's HISKEW enrollment files, with death dates based on death reports validated by the Social Security Administration. We used these death dates to create an indicator variable for one-year mortality.

Our second principal data source is comprehensive information on U.S. hospital characteristics provided by the annual American Hospital Association (AHA) Survey. We restrict our sample to nonfederal, nonrural hospitals that ever reported providing

\footnotetext{
${ }^{8}$ Because Medicare's diagnosis-related group (DRG) payment system for hospitals in theory compensates hospitals on a fixed-price basis per admission for treatment, hospital expenditures might appear to be a poor measure of the resources devoted to a course of care. However, this proposition is not true in practice. The intensity of treatment of most health problems varies enormously, and the DRG system contains important elements of cost sharing (e.g., McClellan, 1997).

${ }^{9}$ We exclude readmissions within 30 days, which may represent a continuation of the initial course of treatment.
} 
general or surgical services. From the survey we obtain information on hospital ownership type, size, teaching status, system membership, and other characteristics that might affect the incentives of the hospital and its managers. We classify hospitals into three ownership categories (nonprofit, for-profit, and public (the omitted group)) and two size categories (small ( $<100$ beds) and large (the omitted group)). We classify hospitals as teaching hospitals if they report at least twenty full-time residents. We also represent whether the hospital is a member of a multi-hospital system with an indicator reflecting system membership (see Madison (2001) for details on the construction of our system variable). Data on hospital characteristics are matched to individual patients based on the hospital to which the patient was initially admitted. Our third data source is The Dartmouth Atlas of Health Care, from which we obtained comprehensive information on the characteristics of HRRs in 1995-1996, including population; the number of Medicare enrollees; the number of acute care beds per 1,000 residents; hospital employees per 1,000 residents; number of registered nurses, total, primary care, and specialist physicians per 1,000 residents; and price-adjusted Medicare reimbursements per enrollee for all noncapitated, inpatient hospital, professional and laboratory, outpatient, and home health services.

We estimate equations (1) and (1a) using OLS on two samples of individuals. We report heteroscedasticity-consistent standard errors that allow for clustering at the HRR level. First, we estimate the equations using as a control group only patients from a matched set of control HRRs that are similar to our entry HRRs in terms of their observable characteristics. To construct this set of control HRRs, we estimate a probit model that had as its unit of observation an HRR. The dependent variable equals one if 
the HRR was one of the five HRRs in our study that experienced entry by a cardiac specialty hospital in 1997 or 1998 and zero otherwise. The independent variables are from The Dartmouth Atlas of Health Care. ${ }^{10}$ With the parameter estimates from this model, we calculate a predicted probability of specialty hospital entry for each HRR, and include in the set of matched control HRRs every HRR with a predicted probability of entry that is within 15 percentage points (either above or below) of the entry HRRs' predicted probabilities. This yields a total of 20 control HRRs.

Second, we estimate the equations using a broader control group consisting of all HRRs in which no specialty hospital entered. In both samples, we weight patients hospitalized in 1996 twice as much as those hospitalized in 1999, because our sample only includes patients hospitalized from July 1-December 31, 1996, but includes patients hospitalized from January 1-December 31, 1999. ${ }^{11}$ We weight patients hospitalized in 1993 five times as much as those hospitalized in 1999, because our 1993 sample is a 20\% random sample of Medicare beneficiaries from the full calendar year.

Table 1 presents descriptive statistics for patients from entry HRRs, patients from matched HRRs without specialty hospital entry (matched control HRRs), and patients from all HRRs without specialty hospital entry (all control HRRs). The first row of Table 1 shows some important differences between entry and control HRRs. First, entry HRRs start the entry period in 1996 with a higher level of one-year hospital expenditures than control HRRs ( $\$ 20,603$ versus $\$ 18,783$ to $\$ 19,734$, depending on control group).

Second, entry HRRs have faster pre-entry hospital expenditure growth (i.e., during 1993-

\footnotetext{
${ }^{10}$ The results of this probit are in Appendix Table 1.

${ }^{11}$ Because $100 \%$ sample Medicare claims are not available before 1996, we could not obtain an expenditure history for patients admitted in the first months of that year. We limited the cohort to patients hospitalized on July 1, 1996 or later in order to obtain 180 days of expenditure history.
} 
96) than do control HRRs over the same period (17.4 percent versus 15.3 or 15.4 percent, depending on control group). Third, entry HRRs have slower post-entry expenditure growth (i.e., during 1996-99) than do control HRRs over the same period (-4.9 percent versus -0.2 or -1.7 percent, depending on control group).

In addition, entry HRRs have a slightly greater proportion of discretionary cardiac admissions than other HRRs, both prior to entry and throughout the study period. Under the assumption that AMI is the only illness we analyze for which admission is entirely nondiscretionary, entry HRRs had approximately one percentage point fewer nondiscretionary admissions than control HRRs. In entry HRRs in 1993, 11.8 percent of patients were admitted with a diagnosis of AMI; in all control HRRs, the comparable figure is 12.7 percent. ${ }^{12}$ Finally, entry HRRs have slightly lower pre-entry mortality than control HRRs. In 1993, one-year mortality for entry HRRs was 22.1 percent; by comparison, one-year mortality in all control HRRs was 23.2 percent. Otherwise, there is little systematic evidence of differences between entry and control HRRs.

\section{RESULTS}

Table 2 presents estimates of $\beta$ from equations (1) and (1a), the effect of specialty hospital entry on treatments and health outcomes for all patients in entry HRRs. Each number in the table represents a separate regression coefficient from a model with a different dependent variable, specification, or control group. The first three columns present estimates from equation (1) and (1a) using the matched control sample; the second three columns present estimates using the all control sample. The first and fourth

\footnotetext{
${ }^{12}$ Classifying only IHD admissions as discretionary does not change this conclusion. Entry HRRs had 1.77 times as many IHD as AMI admissions in 1993 (=0.2050 / 0.1160); by comparison, all control HRRs had $1.63(=0.2036 / 0.1251)$ times as many.
} 
columns present estimates from equation (1) using 1996 as the base year; the second and fifth columns present estimates from equation (1) using 1993 as the base year; and the third and sixth columns present estimates from equation (1a) using all three years.

The first row confirms the basic finding from Table 1: patients from entry HRRs experienced statistically significantly slower growth in their hospital expenditures than patients from control HRRs during the 1996-99 period. Based on the models in Columns 1 and 4, hospital expenditures for patients from entry HRRs grew by \$524 to \$763 less (depending on specification) than did patients from control HRRs. Relative to a base of $\$ 18,750$ (1999 all-control average expenditures), this amounts to 2.8 to 4.1 percent slower growth. ${ }^{13}$

Differences in health outcomes in entry versus control HRRs are generally small and statistically insignificant. ${ }^{14}$ Differences in rates of mortality and readmission with AMI are 0.2 percentage points or less and statistically insignificant. There is evidence of a statistically greater rate of readmission for heart failure of approximately 0.3 percentage points. However, because admission for heart failure is at least partially discretionary, this may represent a combination of differences in outcomes and differences in treatment patterns conditional on outcome. In any event, specialty hospital entry improves efficiency as long as the value of a year without readmission for cardiac complications is less than $\$ 218,000(\$ 218,000=\$ 763$ expenditure reduction from entry / $0.0035 \mathrm{CHF}$ readmission increase).

\footnotetext{
${ }^{13}$ Full results from these regression equations are presented in Appendix Table 2.

${ }^{14}$ Estimating these models as a probit rather than a linear probability model does not change this result. For example, the estimated marginal effect of specialty hospital entry on mortality at the sample average was 0.0979 (standard error 0.3012).
} 
Over a longer time period, however, estimates of the consequences of specialty hospitals crucially depend on assumptions about what would have happened in entry HRRs in the absence of specialty hospital entry. Columns 2 and 4 use a base year of 1993 and assume that the levels of expenditures and outcomes in 1993 would have remained the same in entry HRRs in the absence of entry. Columns 3 and 6 use a base year of 1993 but assume that 1993-96 trends in expenditures and outcomes would have remained the same.

Under the assumption that entry HRRs would have remained at their 1993 levels, specialty hospital entry does not significantly affect cost, but reduces quality of care. Patients in entry versus control HRRs have 1.1 to 1.3 percentage points greater one-year mortality post-entry than they do pre-entry, without consistent offsetting decreases in readmission for AMI or CHF. On a base of 22.5 percent 1996 all-control mortality (Table 1), this amounts to a 4.9 to 5.8 percent increase. However, because 1996 is the most recent year immediately before the entry events in our sample, we believe that 1996 is the most appropriate base year, at least for models that assume that entry HRRs would have retained their levels in the absence of entry.

In contrast, under the assumption that entry HRRs would have retained their 1993-96 trend in expenditures and outcomes in the absence of entry, specialty hospital entry leads to both a reduction in expenditures and a decrease in mortality. According to Columns 3 and 6, entry reduces expenditures by $\$ 1,277$ to $\$ 1,653$ (depending on specification), or 6.8 to 8.8 percent $(1,277$ / 18,750 to 1,653 / 18,750) and mortality by 0.9 to 1.1 percentage points, or 4.0 to 4.9 percent ( 0.9 / 22.5 to 1.1 / 22.5). This reduction 
in mortality is generally accompanied by an increase in readmission with complications, however, indicating that the additional survivors have worse overall cardiac health.

The estimated expenditure consequences of specialty hospital entry are not driven by any obviously spurious factors. They are not driven by any particular HRR. Unpublished estimates of the effect of specialty hospital entry by HRR show that entry has a statistically significant negative expenditure effect in four of the five entry HRRs (the positive effect in the fifth HRR is small and statistically insignificant). Differential changes in Medicare reimbursement rates also do not explain observed expenditure effects. The most important geographic determinant of Medicare payments to acute-care PPS hospitals is the Medicare wage index (see Hackbarth (2002) for discussion), which is constructed so that its average value nationwide is always one. The average Medicare wage index for entry HRRs was 1.016 in 1993, 1.011 in 1996 and 1.005 in 1999 (unpublished calculation based on Medicare wage indices by MSA weighted by the number of admissions from the MSA's analogous HRR in 1996).

Differences in trends in reported diagnosis mix and intensive procedure use also account for virtually none of the gap in expenditures between entry and control HRRs. Omitting controls for diagnosis mix from the regression models underlying Table 2 results in an estimated expenditure effect of entry of $-\$ 530$ (with a standard error of 309) for the matched-control sample. Including controls for procedure use (365-day CATH, PTCA, and CABG indicator variables) in the regression models underlying Table 2 results in an estimated entry effect of $-\$ 514$ (with a standard error of 164) for this sample. To investigate whether differential admissions practices account for the estimated differences in expenditures, we estimated $\beta$ from equations (1) and (1a) on a sample of 
AMI patients only; these estimates appear in Table 3. In particular, because admissions for AMI are generally mandatory, any apparently cost-saving effect of specialty hospitals in Table 2 that was due to discretionary admission of healthier patients in entry HRRs would not appear in Table 3. According to Table 3, the estimated expenditure effects of entry among AMI patients are similar in magnitude to (although less precise than) the effects in the population of cardiac patients as a whole. Along these lines, the estimated outcome effects of entry among AMI patients are not statistically distinguishable from the effects in the population of cardiac patients as a whole.

Table 4 presents additional descriptive statistics and estimates of the effect of admission to a specialty hospital in 1999 on expenditures, intensive procedure use, and health outcomes. The results in this table are based only on patients from the eight HRRs with an open specialty hospital as of January 1, 1999. The first two columns of the table present the average values of treatment intensity, health outcomes, and patient characteristics for patients admitted to specialty and general medical hospitals, respectively. The third column presents the raw difference between the specialty and general hospital populations, and the fourth contains regression estimates of $\beta$ from equation (2).

The descriptive statistics in Table 4 show that specialty hospitals account for a small but significant share of admissions (5.7 percent $=4,520 /(75,000+4,520)$ ) in HRRs where they operate. In addition, consistent with the findings in Table 1, HRRs with a specialty hospital open in 1999 have higher average 1-year cardiac expenditures than other HRRs. This figure- $\$ 20,124(=20,578 * .06+20,095 * .94) —$ is even higher than the average for the five entry HRRs (\$19,595 [Table 1, Column 3]). 
There are substantial differences in the characteristics and outcomes of patients admitted to the two types of hospitals. Patients admitted to a specialty hospital are much more likely to receive an intensive cardiac procedure. They also have substantially better health outcomes. They are much less likely to die within one year (14 percent versus 23.9 percent), and have lower rates of cardiac complications. However, patients initially admitted to specialty versus general hospitals also have very different characteristics on admission. They are younger (by 2.5 years), are much less likely to be female or black, have much lower 180-day prior expenditures (\$1,244 versus $\$ 2,077)$, and are much more likely to be admitted with a diagnosis of IHD (40.3 percent versus 18.3 percent), one of the less-severe illnesses in our sample in terms of expected hospital expenditures. To investigate whether these differences in characteristics could be explained by differences in the diagnosis mix and the types of treatments provided at specialty hospitals, we ran regressions of age, gender, race, and 180-day prior expenditures on an indicator variable for specialty hospital admission and a set of 71 DRG indicator variables (DRGs are a function of diagnosis, severity, and type of treatment, and form the basis for a patient's Medicare reimbursement). These unpublished results show that even controlling for DRGs, patients admitted to specialty hospitals were significantly younger, healthier, and more likely to be white and male.

On net, these effects lead patients admitted to a specialty hospital to have raw 1year hospital expenditures that are \$483 higher than those for patients at general hospitals. Controlling for observable hospital and patient characteristics does not reduce the estimated magnitude of this effect; $\beta$ is estimated to be $\$ 610$, though it is not significantly different from zero at conventional levels of significance. Controlling for 
observable characteristics does reduce differences in procedure rates and health outcomes between specialty and general hospitals by one-half to two-thirds, but eliminates none of them.

\section{CONCLUSION}

What are the effects of specialty hospitals on the costs and quality of care of Medicare beneficiaries? Advocates of these hospitals contend that their focused mission improves quality and lowers costs. Critics contend that these (predominantly for-profit) hospitals concentrate on providing profitable procedures and attracting relatively healthy patients--leaving (predominantly nonprofit) general hospitals with a less-remunerative, sicker patient population.

We find evidence in support of both of these hypotheses. Between 1996 and 1999, patients in HRRs with specialty-hospital entry experienced lower growth in expenditures than patients in control HRRs. This finding is robust to different specifications of the control group, and for AMI as well as other cardiac illnesses. The expenditure savings from entry is not driven by any particular HRR, by differential trends in Medicare reimbursement rates, or by changes in procedure or diagnosis mix. There is only weak evidence of differences in trends in health outcomes in entry versus control HRRs.

Over a longer period, estimates of the efficiency benefits of specialty hospital entry are more dependent on assumptions about what would have happened in entry HRRs in the absence of entry. Under the assumption that entry HRRs would have remained at the same level of expenditures and outcomes as in 1993, entry reduces 
efficiency: entry does not affect cost, but leads to an increase in mortality. Under the assumption that entry HRRs would have retained their 1993-96 trend in expenditures and outcomes in the absence of entry, entry improves efficiency: entry leads to both a reduction in expenditures and a decrease in mortality.

Balancing this, there is evidence that specialty hospitals choose to enter markets with healthier patients, to provide additional intensive treatments of questionable costeffectiveness, and to treat healthier patients within markets -- behaviors that, under reasonable assumptions, may reduce social welfare. Specialty hospitals enter markets that have slightly lower pre-entry levels of mortality. In HRRs with a specialty hospital, those who attend specialty hospitals are much more likely to receive a profitable intensive cardiac procedure in the year after their onset of illness than those who do not, even controlling for demographic characteristics, diagnosis, and Medicare claims history. In addition, specialty hospitals have patient populations that are younger, more likely to be non-black and male, and healthier than their counterparts at general hospitals -characteristics that may be positively correlated with profitability. However, because we do not observe all of the determinants of costs, treatments, and health outcomes, we can not definitively apportion the observed cross-sectional effect of specialty hospital admission into socially-constructive versus socially-harmful effects.

These seemingly-conflicting findings are consistent with other research by one of us presenting a similarly mixed view of for-profit hospitals. For-profits increase marketwide efficiency by improving the performance of competing nonprofits (Kessler and McClellan, 2002) even though they themselves provide additional treatment that has only marginal medical benefit (Becker, Kessler, and McClellan, 2005). Our study reaches a 
similar conclusion. Because the share of specialty hospitals in markets with a specialty hospital is only six percent, market-wide increases in efficiency from specialty hospital entry must come from entry-induced increases in efficiency at general hospitals, even though specialty hospitals engage in behavior that has the potential to reduce social welfare.

Identifying the mechanism through which specialty hospitals improve general hospital performance is an important topic for future research. Future research might also focus on ways to alter the incentives provided by the Medicare reimbursement system to maximize the efficiency benefits from specialty hospitals while minimizing their costs. In addition, further analysis could investigate whether the entry of specialty hospitals impacts the provision of less-remunerative, non-cardiac services by general hospitals. Understanding the impact of specialty hospitals on other aspects of hospitals' decisionmaking will allow for a broader assessment of the implications of specialty hospitals for social welfare. 


\section{REFERENCES}

American Hospital Association, 2002. Annual Survey of Hospitals database.

Becker, D., Kessler, D., McClellan, M., 2005. Detecting Medicare abuse. Journal of Health Economics 24(1), 189-210.

Casalino, L., Devers, K., Brewster, L., 2003. Focused factories? Physician-owned specialty facilities. Health Affairs 22(6), 56-67.

Center for Medicare \& Medicaid Services, 2005. Study of physician-owned specialty hospitals required in Section 507(c)(2) of the Medicare Prescription Drug, Improvement, and Modernization Act of 2003, mimeograph.

Chalkley, M. and Malcomson, J., 2000. Government Purchasing of Health Services in A.J. Culyer and J.P. Newhouse, eds., Handbook of Health Economics, Volume 1A, Chapter 15, North-Holland: Amsterdam.

Cram, P., Rosenthal, G., Vaughan-Sarrazin, M., 2005. Cardiac revascularization in specialty and general hospitals. New England Journal of Medicine 352(14), 1454-1462.

Cromwell, J., Harrow, B., McGuire, T., Ellis, R., 1991. Medicare payment to psychiatric facilities: Unfair and inefficient? Health Affairs 10(2), 124-134.

Dartmouth Atlas of Health Care, 2004. Website, http://www.dartmouthatlas.org/faq.php\#hsa_hrr, accessed November 15, 2004.

Dobson, A., 2003. A Comparative Study of Patient Severity, Quality of Care, and Community Impact at MedCath Heart Hospitals. Lewin Group: Falls Church, VA.

Dranove, D., 1998. Economies of scale in non-revenue producing cost centers: implications for hospital merger. Journal of Health Economics 17(1), 69-83.

Dranove, D., Shanley, M., 1995. Cost reductions or reputation enhancement as motives for mergers: the logic of multihospital systems. Strategic Management Journal 16, 55-74.

Hackbarth, Glenn M. 2002. Adjusting Medicare Payments for Local Market Input Prices. Testimony before the Subcommittee on Health, Committee on Ways and Means, U.S. House of Representatives, July 23, 2002, http://www.medpac.gov/publications/congressional_testimony/072302(WM)local_input_ prices.pdf.

Hannan, E., Kilburn, H., Bernard, H., O’Donnell, J., Lukacik, G., Shields, E., 1991. Coronary artery bypass graft surgery: The relationship between inhospital mortality rate and surgical volume after controlling for clinical risk factors. Medical Care 29(11), 10941107. 
Hannan, E., Racz, M., Ryan, T., McCallister, B., Johnson, L., Arani, D., Guerci, A. Sosa, J., Topol, E., 1997. Coronary angioplasty volume-outcome relationships for hospitals and cardiologists. Journal of the American Medical Association 277(11), 892-898.

Hansmann, H., Kessler, D., McClellan, M., 2003. “Ownership Form and Trapped Capital in the Hospital Industry,” in Edward Glaeser, ed., The Governance of Not-for-Profit Firms, University of Chicago Press: Chicago, IL.

Herzlinger, R., 1997. Market Driven Health Care, Addison Wesley, Reading, MA.

Held, P., Pauly, M., 1983. Competition and efficiency in the end stage renal disease program. Journal of Health Economics 2(2), 95-118.

Ho, V., 2005. Does certificate of need affect cardiac outcomes and costs, working paper.

Horwitz, J., 2005. Making profits and providing care: comparing non-profit, for-profit, and government hospitals. Health Affairs 24(3), 790-801.

Huckman, R., Pisano, G., 2005. The firm specificity of individual performance: Evidence from cardiac surgery. Management Science, forthcoming.

Joskow, P., 1980. The effects of competition and regulation on hospital bed supply and the reservation quality of the hospital. Bell Journal of Economics 11(2), 421-447.

Kessler, D., McClellan, M., 2002. "The Effects of Hospital Ownership on Medical Productivity,” RAND Journal of Economics 33(3) 488-506.

Luft, H., Bunker, J., Enthoven, A., 1979. Should operations be regionalized? The empirical relation between surgical volume and mortality. New England Journal of Medicine 301(25), 1364-1369.

Luft, H., Hunt, S., Maerki, S., 1987. The volume-outcome relationship: Practice-makesperfect or selective-referral patterns? Health Services Research 22(2), 157-182.

Lynk, W., Longley, C., 2002. The effect of physician-owned surgicenters on hospital outpatient surgery. Health Affairs 21(4), 215-221.

Madison, K., “The Relationship Between Multihospital System Membership and Treatments, Costs, and Outcomes of Medicare Patients with Acute Myocardial Infarction,” PhD. Thesis, Stanford University, 2001.

McClellan, M., 1997. Hospital reimbursement incentives: An empirical approach. Journal of Economics and Management Strategy 6(1), 91-128. 
McClellan, M., McNeil, B., Newhouse, J., 1994. Does more intensive treatment of acute myocardial infarction in the elderly reduce mortality? Journal of the American Medical Association 272(1994), 859-866.

Robinson, J., Luft, H., 1985. The impact of hospital market structure on patient volume, average length of stay, and the cost of care. Journal of Health Economics 4(4), 333-356.

Skinner, W., 1974. The focused factory. Harvard Business Review, May-June, 113-120.

United States General Accounting Office, 2003a. Specialty Hospitals: Information on National Market Share, Physician Ownership, and Patients Served, Washington, D.C.

United States General Accounting Office, 2003b. Specialty Hospitals: Geographic Location, Services Provided, and Financial Performance, Washington, D.C.

Winter, A., 2003. Comparing the mix of patients in various outpatient surgery settngs. Health Affairs 22(6), 68-75. 
Table 1: Average Treatment Intensity, Health Outcomes, and Patient Characteristics in HRRs With and Without Specialty Hospital Entry Between 1996 and 1999

Measures of treatment intensity 1-year hospital expenditures

1-day CATH

365-day CATH

1-day PTCA

365-day PTCA

1-day CABG

365-day CABG

Measures of health outcomes

365-day mortality

365-day CHF readmission

365-day AMI readmission

Patient characteristics

\section{Age}

Percent female

Percent black

180-day prior hospital expenditure

Diagnosis of AMI

Diagnosis of IHD

Diagnosis of dysrythmia

Diagnosis of heart failure

Diagnosis of other heart condition

Diagnosis of circulatory sys cond

Diagnosis of cerebrovascular

Number of observations

\begin{tabular}{ccccc} 
HRRs with Specialty Hospital Entry \\
\hline $1993 \quad 1996 \quad 1999 \quad$ \% change \% change
\end{tabular}

(1)$$
\text { (2) }
$$

(3)

(4)

(5)

$\begin{array}{lll}17,549 & 20,603 & 19,595\end{array}$

$\begin{array}{lll}0.0781 & 0.1048 & 0.1207\end{array}$

$\begin{array}{lll}0.2116 & 0.2412 & 0.2533\end{array}$

$\begin{array}{lll}0.0190 & 0.0359 & 0.0524\end{array}$

$\begin{array}{lll}0.0596 & 0.0826 & 0.1036\end{array}$

$\begin{array}{lll}0.0138 & 0.0256 & 0.0256\end{array}$

$\begin{array}{lll}0.0708 & 0.0867 & 0.0792\end{array}$

$\begin{array}{lll}0.2205 & 0.2341 & 0.2348\end{array}$

$\begin{array}{lll}0.0974 & 0.0945 & 0.0966\end{array}$

$\begin{array}{lll}0.0238 & 0.0229 & 0.0242\end{array}$

$-0.3 \%$
$-0.1 \%$

$\begin{array}{rr}17.4 \% & -4.9 \% \\ 2.7 \% & 1.6 \%\end{array}$

$2.7 \%$

$3.0 \%$

$1.7 \%$
$2.3 \%$

$1.2 \%$

$1.6 \%$

$1.2 \%$

$1.7 \%$

$2.1 \%$

$0.0 \%$

$-0.7 \%$

$\begin{array}{lll}77.29 & 77.79 & 78.35\end{array}$

$\begin{array}{lll}0.5532 & 0.5573 & 0.5618\end{array}$

$\begin{array}{lll}0.1126 & 0.1055 & 0.1026\end{array}$

$\begin{array}{lll}1,665 & 1,931 & 2,006\end{array}$

$\begin{array}{lll}0.1175 & 0.1094 & 0.1076\end{array}$

$\begin{array}{lll}0.2054 & 0.2019 & 0.1944\end{array}$

$\begin{array}{lll}0.1238 & 0.1230 & 0.1383\end{array}$

$\begin{array}{lll}0.1951 & 0.1826 & 0.1834\end{array}$

$\begin{array}{lll}0.0654 & 0.0718 & 0.0780\end{array}$

$\begin{array}{lll}0.0594 & 0.0611 & 0.0623\end{array}$

$\begin{array}{lll}0.2335 & 0.2502 & 0.2360\end{array}$

$\begin{array}{lll}11,843 & 28,170 & 55,109\end{array}$

\section{All US Without Specialty Hospital Entry}

$1993 \quad 1996$

(6) (7)

(8)

(9)

$\begin{array}{ll}16,292 & 18,783 \\ 0.0738 & 0,1000\end{array}$

$\begin{array}{ll}0.0738 & 0.1000 \\ 0.2157 & 0.2428\end{array}$

$\begin{array}{ll}0.0253 & 0.0419\end{array}$

$0.0692 \quad 0.0912$

$0.0193 \quad 0.0289$

$0.0780 \quad 0.0902$

18,750

0.1205
0.2601

0.2601
0.0592

0.1116

0.0303

0.0856

$15.3 \%$

$2.6 \%$

$$
2.7 \%
$$

$2.7 \%$
$1.7 \%$

$2.2 \%$

$1.0 \%$

$1.2 \%$

$\begin{array}{ll}0.2318 & 0.2311\end{array}$

$\begin{array}{lll}0.2 \% & 0.0895 & 0.0888\end{array}$

0.2295

0.0886

$-0.1 \%$

$-0.1 \%$

$0.6 \%$
$0.4 \%$
$-0.7 \%$
$16.0 \%$
$-0.8 \%$
$-0.4 \%$
$-0.1 \%$
$-1.3 \%$
$0.6 \%$
$0.2 \%$
$1.7 \%$

$0.4 \%$
$-0.7 \%$
$16.0 \%$
$-0.8 \%$
$-0.4 \%$
$-0.1 \%$
$-1.3 \%$
$0.6 \%$
$0.2 \%$
$1.7 \%$

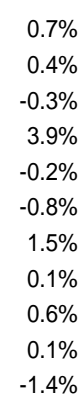

$\begin{array}{rr}77.09 & 77.48 \\ 0.5431 & 0.5459 \\ 0.0798 & 0.0780 \\ 1,439 & 1,651 \\ 0.1265 & 0.1219 \\ 0.2050 & 0.2047 \\ 0.1138 & 0.1154 \\ 0.1939 & 0.1758 \\ 0.0709 & 0.0728 \\ 0.0565 & 0.0614 \\ 0.2334 & 0.2481 \\ 311,453 & 816,390\end{array}$

77.95

0.5473

0.0790

1,752
0.1238

0.1986

0.1260

0.1810

0.0767

0.0604

0.2335

$0.5 \%$
$0.3 \%$
$-0.2 \%$
$14.7 \%$
$-0.5 \%$
$0.0 \%$
$0.2 \%$
$-1.8 \%$
$0.2 \%$
$0.5 \%$
$1.5 \%$

1993-96 1996-99

(10)

$-0.2 \%$
$2.1 \%$

$2.1 \%$
$1.7 \%$

$1.7 \%$
$1.7 \%$

$2.0 \%$

$0.1 \%$

$-0.5 \%$

$-0.2 \%$

$-0.2 \%$
$0.0 \%$

$0.2 \%$

0.097

$0.0260 \quad 0.0264$

$$
\begin{array}{r}
0.6 \% \\
0.1 \% \\
0.1 \% \\
6.1 \% \\
0.2 \% \\
-0.6 \% \\
1.1 \% \\
0.5 \% \\
0.4 \% \\
-0.1 \% \\
-1.5 \%
\end{array}
$$

$\begin{array}{rr}77.21 & 77.77 \\ 0.5520 & 0.5636 \\ 0.0852 & 0.0888 \\ 1,634 & 1,927 \\ 0.1215 & 0.1191 \\ 0.2048 & 0.2054 \\ 0.1103 & 0.1133 \\ 0.2078 & 0.1854 \\ 0.0679 & 0.0719 \\ 0.0564 & 0.0585 \\ 0.2312 & 0.2465 \\ 29,369 & 73,812\end{array}$

$\begin{array}{rrr}78.29 & 0.7 \% & 0.7 \% \\ 0.5631 & 1.2 \% & 0.0 \% \\ 0.0898 & 0.4 \% & 0.1 \% \\ 1,992 & 17.9 \% & 3.4 \% \\ 0.1188 & -0.2 \% & 0.0 \% \\ 0.1941 & 0.1 \% & -1.1 \% \\ 0.1251 & 0.3 \% & 1.2 \% \\ 0.1934 & -2.2 \% & 0.8 \% \\ 0.0787 & 0.4 \% & 0.7 \% \\ 0.0569 & 0.2 \% & -0.2 \% \\ 0.2330 & 1.5 \% & -1.4 \% \\ 145,964 & & \end{array}$


Table 2: Estimated Effect of Specialty Hospital Entry on Expenditures, Treatments, and Outcomes, Elderly Medicare Beneficiaries with Cardiac Illness

\begin{tabular}{ccc}
\multicolumn{3}{c}{ Matched Control HRRs } \\
\hline & & 93,96, and 99 \\
1996 and & 1993 and & data w/control \\
1999 data & 1999 data & for linear trend
\end{tabular}

(1)

Measures of treatment intensity

1-year hospital expenditures

1-day CATH

365-day CATH

1-day PTCA

365-day PTCA

1-day CABG

365-day CABG

Measures of health outcomes

365-day mortality

365-day CHF readmission

365-day AMI readmission

Number of observations
(2)

(3)

$-1,277$ **
$(510)$
-0.3131
$(0.6518)$
-0.8819
$(0.7894)$
0.2739
$(0.4561)$
0.2784
$(0.7925)$
-0.3942
$(0.2592)$
-0.9989 **
$(0.4493)$

-1.1425 **

$(0.5227)$

0.8361 **

(0.3301)

0.0118

(0.2218)

$(0.1642)$

303,055

344,267

\begin{tabular}{ccc}
\multicolumn{3}{c}{ All Control HRRs } \\
\hline & 1993 and & 93,96, and 99 \\
1996 and & 1999 data & data w/control \\
1999 data & &
\end{tabular}

(4)

(5)

(6)

-763 ***
$(246)$
-0.4447
$(0.2791)$
-0.3090
$(0.3572)$
-0.0393
$(0.1679)$
0.1897
$(0.1653)$
$-0.1480 *$
$(0.0871)$
-0.2299
$(0.1475)$

$$
101
$$

(453)

$-0.1344$

(0.4597)

0.3975

(0.6030)

0.0870

(0.4809)

0.4872

(0.4094)

0.0902

(0.0851)

0.2944

(0.2789)

$-1,653$ ***
$(405)$
$-0.7531 *$
$(0.4233)$
$-0.9599 *$
$(0.5395)$
-0.1692
$(0.2875)$
-0.0663
$(0.5111)$
-0.3968 **
$(0.1879)$
$-0.7233 * \star *$
$(0.2156)$

0.1721
$(0.1398)$
0.3471
$(0.0879)$
-0.0352
$(0.1321)$

1.2652 ***

(0.3435)

0.0580

(0.1998)

$-0.1403$

(0.1845)

-0.8912 ***

$(0.1807)$

0.6337 ***

$(0.2273)$

0.0817

(0.1717)

$2,596,835$

$2,075,571$

$2,920,131$

Note: ***,**, and * denote significance at the $1 \%, 5 \%$, and $10 \%$ levels, respectively. Coefficients from models with discrete dependent variables multiplied by 100 for ease of interpretation. 
Table 3: Estimated Effect of Specialty Hospital Entry on Expenditures, Treatments, and Outcomes, Elderly Medicare Beneficiaries with AMI, 1993-99

\begin{tabular}{ccc} 
& Matched Control HRRs \\
\hline & & 93,96, and 99 \\
1996 and & 1993 and & data w/control \\
1999 data & 1999 data & for linear trend
\end{tabular}

(1)

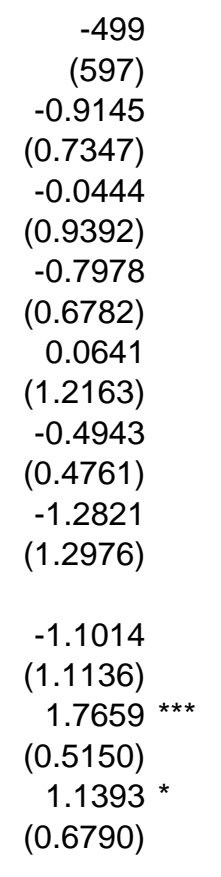

(2)

$$
\begin{array}{r}
-352 \\
(453) \\
-0.2517 \\
(1.5993) \\
-2.1522 \\
(1.8258) \\
0.5121 \\
(1.4482) \\
0.6300 \\
(1.6317) \\
-0.0329 \\
(0.3810) \\
-1.8013 \\
(1.5610) \\
\\
0.3320 \\
(1.9069) \\
-0.3871 \\
(0.6142) \\
-0.6965 \\
(0.8443)
\end{array}
$$$$
\text { (3) }
$$

1996 and

(4)

$$
\begin{gathered}
-654 \\
(1002) \\
-1.1682 \\
(1.8619) \\
2.2761 \\
(1.8750) \\
-1.9482 \\
(1.7771) \\
-0.5847 \\
(2.0259) \\
-0.8939 \\
(0.8564) \\
-0.5246 \\
(1.5227) \\
\\
-2.7772 \\
(2.0229) \\
4.1933 * \star * \\
(1.1466) \\
2.8770 \star \star * \\
(0.9254) \\
\end{gathered}
$$

28,230

$-1,011$ **
$(425)$
-0.3883
$(0.4796)$
0.4004
$(0.7723)$
$-0.8299 *$
$(0.4439)$
0.3485
$(0.4694)$
-0.5487
$(0.4258)$
-0.6091
$(1.1101)$

-0.5590
$(0.6589)$
$1.0035 * \star$
$(0.3541)$
0.7667
$(0.5779)$

40,104
All Control HRRs

$\begin{array}{ll}1993 \text { and } & 93,96, \text { and } 99 \\ 1999 \text { data } & \text { data w/control } \\ \text { for linear trend }\end{array}$

(5)

(6)

$\begin{array}{rc}-312 & -1,740 * * \\ (334) & (778) \\ -0.4041 & -0.3578 \\ (0.9237) & (0.9898) \\ -1.9614 & 3.0149 \\ (1.5364) & (1.5316) \\ 0.3754 & -1.9377 \\ (1.2249) & (1.2723) \\ 1.2341 & -0.6108 \\ (1.2996) & (0.6049) \\ -0.1755 & -0.9364 \\ (0.2306) & (0.7884) \\ -1.6780 & 0.5337 \\ (1.1543) & (1.2173) \\ & \\ 1.2489 & -2.3911 * \\ (1.6560) & (1.3624) \\ 0.1943 & 2.0285 * * \\ (0.4223) & (0.9172) \\ -0.6149 & 2.2103 * \star * \\ (0.6491) & (0.8157) \\ 256,839 & 359,453\end{array}$

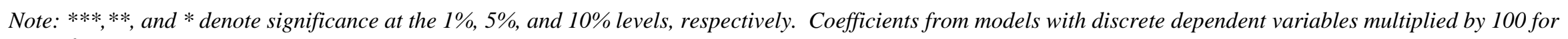
ease of interpretation. 
Table 4: Unadjusted and Regression-Adjusted Differences in Expenditures, Treatments, and Outcomes for Patients Admitted to Specialty and General Hospitals, Elderly Medicare Beneficiaries with Cardiac Illness Who Live in an HRR with a Specialty Hospital, 1999

Measures of treatment intensity 1-year hospital expenditures

1-day CATH

365-day CATH

1-day PTCA

365-day PTCA

1-day CABG

365-day CABG

Measures of health outcomes 365-day mortality

365-day CHF readmission

365-day AMI readmission

Patient characteristics

\section{Age}

Percent female

Percent black

180-day prior hospital expenditure

Diagnosis of AMI

Diagnosis of IHD

Diagnosis of dysrythmia

Diagnosis of heart failure

Diagnosis of other heart condition

Diagnosis of circulatory sys cond

Diagnosis of cerebrovascular

Number of observations
Speciality
Hospital Mean

(1)

$$
20,578
$$

0.3201

0.4681

0.1564

0.2206

0.1027

0.2064

0.1403

0.0772

0.0206

76.04

0.4591

0.0303

1244

0.0823

0.4033

0.1232

0.0973

0.0918

0.0896

0.1124

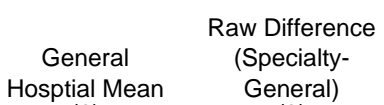

(2)

20,095

0.1009

0.2390

0.0417

0.0938

0.0201

0.0704

0.2387

0.0993

0.0260

78.53

0.5632

0.0916

2077

0.1104

0.1830

0.1387

0.1896

0.0818

0.0578

0.2388

75,000
(3)

483

0.2192

0.2291

0.1147

0.1268

0.0826

0.1360

$-0.0984$

$-0.0221$

$-0.0054$

Effect of Specialty

Hospital

(Controlling for

Hospital and

Patient

Characteristics)

(4)

Note: ${ }^{* *}, * *$, and $*$ denote significance at the $1 \%, 5 \%$, and $10 \%$ levels, respectively. Coefficients from models with discrete dependent variables multiplied by 100 for ease of interpretation. 


\section{Appendix Table 1: Probit Estimates of the Effect of HRR Characteristics on the Probability of Specialty Hospital Entry}

Medicare enrollees ('000)
Population ('000,000)
Acute care beds/1000 residents
Hospital employees/1000 residents
RNs/1000 residents
Medicare total noncapitated payment/enrollee
Medicare inpatient hospital payment/enrollee
Medicare professional/lab payment/enrollee
Medicare outpatient payment/enrollee
Medicare home health payment/enrollee
MDs/1000 residents
Primary care MDs/1000 residents
Specialist MDs/1000 residents

$\begin{array}{rr}\text { Parameter } & \text { Standard Error } \\ 0.0051 & 0.0038 \\ -0.0836 & 0.3270 \\ -0.4055 & 0.7455 \\ 0.4016 & 0.2753 \\ -0.8506 & 1.0313 \\ 0.0057 & 0.0025 \\ -0.0062 & 0.0030 \\ -0.0059 & 0.0031 \\ -0.0138 & 0.0070 \\ -0.0060 & 0.0031 \\ 0.3782 & 1.3379 \\ -0.3517 & 1.3352 \\ -0.3877 & 1.3398 \\ 306 & \\ & \end{array}$




\section{Appendix Table 2: Regression Estimates of the Effect of Specialty Hospital Entry, Patient Characteristics, and Hospital Characteristics on Expenditures}

\begin{tabular}{|c|c|c|c|c|}
\hline \multirow{3}{*}{ Coefficient estimate } & \multicolumn{2}{|c|}{ Matched Control HRRs } & \multicolumn{2}{|c|}{ All Control HRRs } \\
\hline & Parameter & Standard Error & Parameter & Standard Error \\
\hline & & & & \\
\hline Entry HRR & -524 & 306 & -763 & 246 \\
\hline age $65-69$ & 3172 & 193 & 3386 & 79 \\
\hline age $70-74$ & 3436 & 219 & 3637 & 73 \\
\hline age $75-79$ & 3358 & 270 & 3544 & 65 \\
\hline age $80-84$ & 2621 & 169 & 2744 & 52 \\
\hline age $85-89$ & 1482 & 141 & 1622 & 47 \\
\hline female & -878 & 102 & -927 & 41 \\
\hline black & 1813 & 265 & 1180 & 110 \\
\hline diagnosis of AMI & 4006 & 429 & 3910 & 118 \\
\hline diagnosis of IHD & 1751 & 292 & 2231 & 95 \\
\hline diagnosis of dysrythmia & -2845 & 181 & -2679 & 66 \\
\hline diagnosis of heart failure & 823 & 307 & 675 & 87 \\
\hline diagnosis of other heart cond & 2149 & 321 & 2589 & 135 \\
\hline diagnosis of circulatory disorder & 6297 & 419 & 6359 & 115 \\
\hline for-profit hospital & 1007 & 337 & 719 & 149 \\
\hline nonprofit hospital & -291 & 316 & -138 & 106 \\
\hline system hospital & 601 & 205 & 328 & 86 \\
\hline large hospital & 1392 & 268 & 1285 & 89 \\
\hline teaching hospital & 1781 & 424 & 2303 & 154 \\
\hline year=1999 & -243 & 187 & 48 & 63 \\
\hline $\begin{array}{l}\text { 180day prior hospital expenditure } \\
\text { ('000) }\end{array}$ & 206 & 13 & 189 & 4 \\
\hline Number of observations & 303,055 & & & \\
\hline
\end{tabular}

